\title{
Occurrence of Oral Ulcerations in Patients undergoing Orthodontic Treatment: A Comparative study
}

\author{
Dr Apeksha Mainali \\ Lecturer, Department of Oral Medicine \& Radiology \\ Kantipur Dental College, Kathmandu, Nepal
}

Correspondence: drmainaliapeksha@gmail.com

\section{ABSTRACT}

Introduction: Intra-oral and extra-oral tissues are at risk of damage during orthodontic treatment, most commonly oral ulcerations. Clinicians should assess and monitor every aspect of patient's treatment procedure to achieve an uneventful and successful final result.

Objective: To evaluate occurrence of oral ulcerations in patients undergoing orthodontic treatment. To evaluate the most common type of ulceration and to assess the management of such ulcerations by the orthodontists.

Materials \& Method: A questionnaire-based study was used among Nepalese and international orthodontists. Data were analyzed statistically using descriptive analysis and Chi-square test, $\mathrm{p}<0.05$ was considered to be significant with a confidence interval of $95 \%$.

Result: Most common oral ulceration encountered during orthodontic treatment was traumatic ulceration which was managed by symptomatic measures. There was a statistically significant difference in the method of education to the patients among national and international orthodontists.

Conclusion: Careful use of instruments, careful fitting and adjustment of the appliances should be done to avoid oral ulcerations during orthodontic treatment. Topical medicines can be used for management of such ulcers. Nepalese orthodontists should focus on using audio-visual aids for patient education as it has great promise in enhancing patient understanding and in prompting behavioral change.

Key words: education method, oral ulceration, topical medicine

\section{INTRODUCTION}

Orthodontic treatment helps in improving facial and dental aesthetics; above all it builds self-esteem of the patient. If correcting malocclusion is of benefit, advantages it offers should outweigh any possible damage. The potential hazards of orthodontic treatment are three-fold: tissue damage; treatment failure; greater predisposition to dental disorders.' Clinicians should ensure that majority of the patients are benefitted with vigilant case selection, diagnosis, treatment planning, monitoring and timely intervention. During orthodontic treatment, both intra-oral and extra-oral tissues are at risk of damage. Laceration to gingiva and oral mucosa may present as ulceration. Archwires, brackets, bands and long unsupported stretches of wire resting against the lips can also lead to ulcerations. ${ }^{2}$ Excessive muscular activities of the cheek or tongue may also act as triggers. Therefore the clinicians should assess and monitor every aspect of orthodontic procedure during and after treatment to achieve an uneventful, secure, and successful final result. ${ }^{3}$
The objective of this study were to evaluate the occurrence of oral ulcerations in patients undergoing orthodontic treatment, to assess the most common type of ulceration and their management methods, and to evaluate the attitude of orthodontists towards management of patients.

\section{MATERIALS AND METHOD}

A survey instrument was developed comprising of a questionnaire in English. The study was done amongst Nepalese and international orthodontists. The questionnaire study was initiated only after validation of the questionnaire for reliability. The study was designed to assess the attitude and practice of Orthodontists regarding management of oral ulcerations.

Questions were asked regarding whether Orthodontists educated their patients towards possible oral complications before initiating the treatment, the aid they used in educating the patients, the necessary precautions to prevent ulcerations in orthodontic patients, the common oral complaints they 
encountered during orthodontic treatment, the most frequent type of oral ulcerations they encountered, how they handled and treated the ulcerations, whether they entertained emergency calls regarding oral ulcerations and how they addressed such problems.

Convenient sampling was taken for sample size determination. Only qualified Orthodontists from Nepal and abroad were included in the study. The study was done during januaryjuly 2013. Informed verbal consent was taken from each participant before administration of the questionnaire. Willing participants were informed in detail about the research project through telephonic conversation or e-mail. Privacy of the clinicians was ensured during filling of the questionnaires. The questionnaire was subjected to statistical analysis. Data were fed to SPSS software version 17.0 and were analyzed statistically using descriptive analysis and Chi-square test, $p<0.05$ was considered to be significant with a confidence interval of $95 \%$.

\section{Result}

The total sample size was 120, out of which 39 were Nepalese Orthodontists and 81 were International orthodontists (Table 1).
The study found that, all Orthodontists educated their patients regarding possible oral complications before initiating treatment and felt the necessity for taking precautions to prevent ulcerations in patients undergoing orthodontic treatment. Most of the Nepalese orthodontists followed conventional method of patient education like verbal (61.50\%) and leaflet (10.30\%) (Graph 1). Orthodontists following verbal and leaflet method of education were combined for the purpose of cross tabulation in statistical analysis. There was a significant difference in the method of education to the patients among national and international Orthodontists (Table 2).

The oral problems encountered during orthodontic treatment were oral ulcerations $40.8 \%$, problems to dental hard tissues $29.2 \%$, periodontal problems $25.8 \%$ and TMJ pain $9.2 \%$ (Graph 2). Amongst oral ulcerations, the most frequent ones were traumatic ulcerations $(60.80 \%)$ followed by apthous ulcerations (8.30\%) (Graph 3). The study showed that most of the orthodontists use supportive management for oral ulcerations by themselves (Table 3). Similarly most of the orthodontists addressed emergency call regarding oral ulcers thorough telephonic conversation (60\%) and $53 \%$ of the orthodontists gave appointment on next day (Table 4).

Table 1: Nationality and gender distribution of Orthodontist

\begin{tabular}{|l|c|c|c|}
\hline \multicolumn{1}{|c|}{ Orthodontists } & Male & Female & Total \\
\hline Nepali & 33 & 6 & 39 \\
\hline International & 56 & 25 & 81 \\
\hline
\end{tabular}

Table 2: Patient education method among Orthodontists

\begin{tabular}{|l|c|c|c|c|}
\hline & Verbal +Leaflet & Audio-visual & Total & $p$-value \\
\cline { 1 - 4 } Nepali & 28 & 11 & 39 & \multirow{2}{*}{$0.002^{*}$} \\
\hline International & 34 & 47 & 81 & \\
\hline
\end{tabular}

*Statistically significant at $p<0.05$

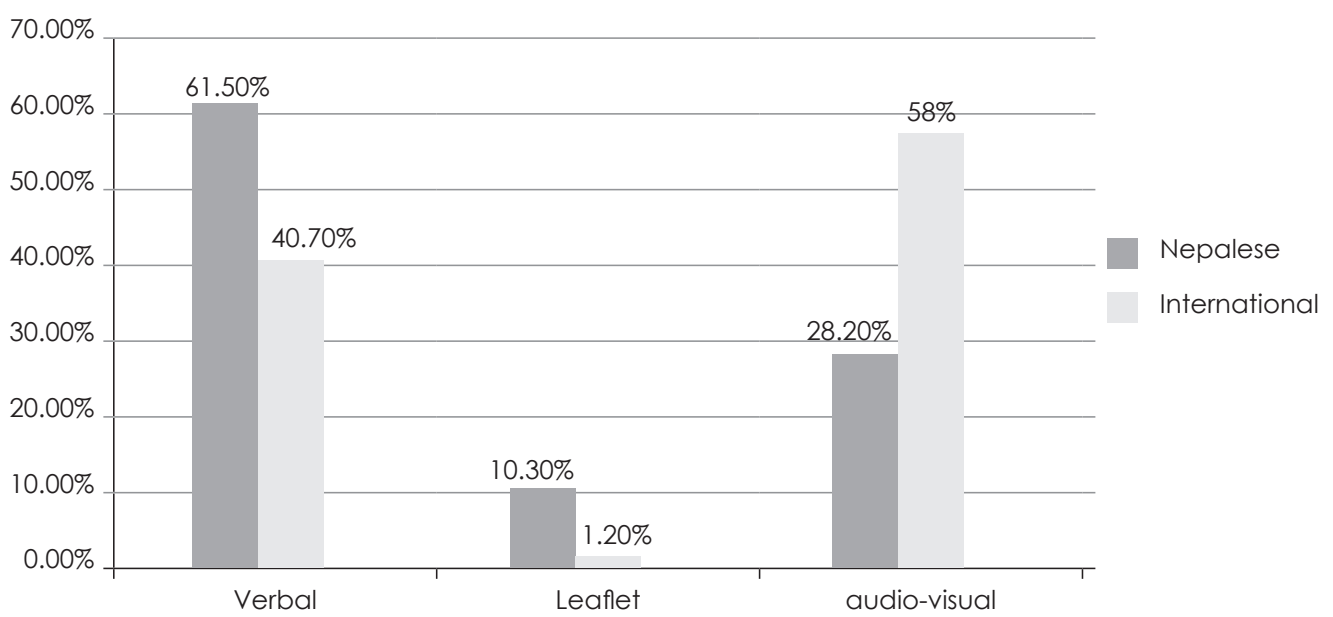

Graph 1: Education methods used by Orthodontists 


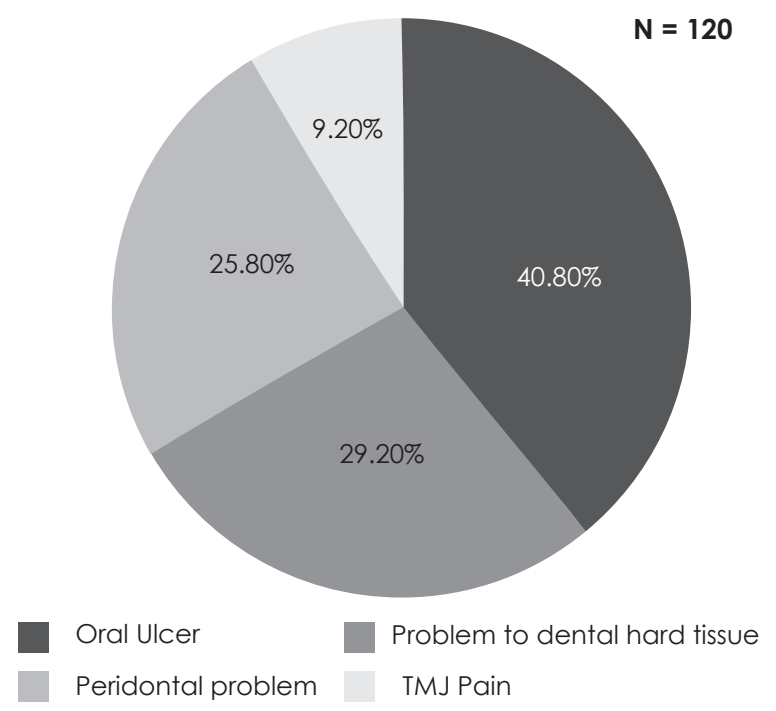

Graph 2: Distribution of oral problems encountered during orthodontic treatment

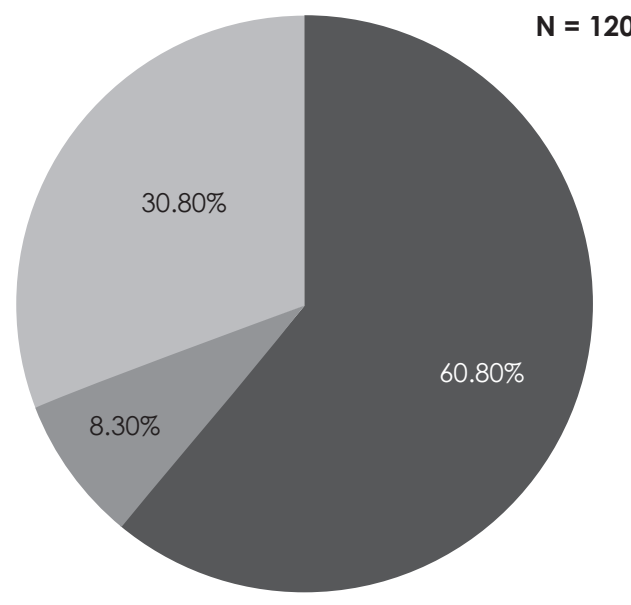

Traumatic Ulcers

Apthous Ulcers

Both

Table 3: Management methods of oral ulcers practiced by Orthodontists

\begin{tabular}{|l|c|c|}
\hline & Frequency (N) & Percentage (\%) \\
\hline Supportive Measures & 55 & 45.8 \\
\hline Definitive Medication & 7 & 5.8 \\
\hline Appliance Modification & 18 & 15 \\
\hline Combination Therapy & 40 & 33.3 \\
\hline
\end{tabular}

Table 4: Response of Orthodontists towards emergency calls regarding oral ulcers

\begin{tabular}{|l|c|c|}
\hline & Frequency (N) & Percentage (\%) \\
\hline Call the patient immediately & 7 & 5.8 \\
\hline Telephonic conversation & 60 & 50 \\
\hline Give appointment the next day & 53 & 44.2 \\
\hline
\end{tabular}

\section{DISCUSSION}

Oral mucosa is thin membrane causing any vesicles and bullae to break rapidly into ulcers. These ulcers are easily traumatized from teeth and food particles, and they become secondarily infected by the oral flora. ${ }^{4}$ Orthodontic treatment carries with it the risks of tissue damage, treatment failure and increased predisposition to dental disorders.' It is important that the practitioners are aware of these risks. Some patients are more at risk than others; they need to be identified early and managed appropriately to avoid adverse sequelae. Gingival inflammation, erosion, ulceration, and contusion were the most common findings in orthodontic patients in a study conducted by Baricevic et al; 5 their reported incidence is consistent with the finding of the present study.
Patients may get oral ulcers secondary to rubbing of the lips and cheeks on brackets, bands or cleats, as they become accustomed to fixed appliances. Occasionally, palatal or lingual arches may cause trauma to the palate or tongue.' In this study, most of the ulcerations were seen in the first appointment following bonding. Some of the orthodontists in the study even gave details of incidences of stomatitis due to nickel allergy. In such cases, ceramic brackets or rubbers were used as protective barrier. In general, careful use of instruments, careful fitting and adjusting of appliances should be done to avoid sharp edges. It was seen from this study that most of the orthodontists gave supportive treatment to the patients with oral ulcerations which shows that there is necessity for proper management of ulcers. Though the oral tissues quickly toughen up to a new appliance, proper 
Table 5: Management of Oral Ulcerations following Orthodontic Treatment

\begin{tabular}{|l|l|}
\hline Coating agents & Aluminum chloride, Aluminum hydroxide, Magnesium hydroxide, Hydroxypropylcellulose, Sucralfate \\
\hline Lip lubricants & Water-based lubricants, lanolin \\
\hline Topical anesthetics & $\begin{array}{l}\text { Dyclonine hydrochloride, Xylocaine hydrochloride, Benzocaine hydrochloride, Diphenhydramine } \\
\text { hydrochloride }\end{array}$ \\
\hline Analgesic agents & Benzydamine hydrochloride \\
\hline Newer agents & Tetracycline mouthwash, Prednisolone mouthwash, Alcohol-free povidone-iodine mouthwash \\
\hline
\end{tabular}

management is required. The management can be divided into preventive and definitive therapy. 6.7 The use of dental wax over the bracket may significantly reduce trauma and discomfort. Rubber tubing on the unsupported arch wire also reduces the risk of iatrogenic damage. Furthermore $^{2}$ careful rounding-off of sharp edges of the appliance can also be helpful. Table 5 lists the various medicines used for the treatment of oral ulcerations. ${ }^{4.8}$ All the orthodontists in this study educated the patients but a significant statistical difference was found in the method of education by national and international orthodontists. Verbal education to the patients was predominantly seen in national orthodontists while audio-visual means of education was commonly followed by international orthodontists. This can be attributed to the lack of use of modern amenities amongst the national orthodontists. Audio-visual teaching methods help enhancing patient understanding. This significance of good communication should be recognized as audio-visual aids is the best tool for making teaching effective and the best dissemination of knowledge. Most of the Orthodontists in this study handled emergency calls regarding oral ulcerations through telephonic calls and gave appointment the next day rather than seeing the patients immediately. Practice of attending patients immediately should be reinforced among orthodontists to rule out unwanted surprises and to provide safe and even better service to the patients.

\section{CONCLUSION}

It is important to assess the risks of treatment and potential gain. Thus orthodontists must balance various aspects of treatment before proceeding treatment and have cushion against uncertainty. Nepalese orthodontists should focus on using audio-visual aids for patient education as it is an effective method in both enhancing patient understanding and in prompting behavioral change.

\section{ACKNOWLEDGEMENT}

My sincere gratitude to all national and international Orthodontists who participated in the study. My special thanks to Dr. Rabindra Man Shrestha, Associate Professor and Head of Department of Orthodontics for his guidance in the preparation of the Questionnaire and Dr. Sujita Shrestha, Lecturer, Department of Community Dentistry for her guidance in statistical analysis.

\section{OJN}

\section{REFERENCES}

1. Ellis P, Benson P. Potential hazards of orthodontic treatment what your patient should know. Dent Update 2002; 29:492-6.

2. Kvam E, Bondevik O, Gjerdet NR. Traumatic ulcers and pain during orthodontic treatment. Community Dent Oral Epidemiol 1989; $17(3): 154-7$.

3. Profit WR. Orthodontic treatment planning: Limitations, Controversies and special problems. Contemporary Orthodontics, 4th ed. Elsevier Science. 2007; p 268-330.

4. Greenberg M, Glick M. Ulcerative, vesicular and bullous lesions. Burket's Oral Medicine Diagnosis and Treatment, 10th ed. Elsevier Science. 2003; p 46-59.

5. Baricevic M, Mravak-Stipetic M, Majstorovic M, Baranovic M, Baricevic D, Loncar B. Oral mucosal lesions during orthodontic treatment. Int J Paediatr Dent. 2011; 21(2):96-102.

6. Shaw WC, Maddy, Griffiths S, Price C. Chlorhexidine and traumatic ulcers in orthodontic patients. Eur J Orthod. 2010; 6(1):137-140.

7. Kvam E, Gjerdet N, Bondevik O. Traumatic ulcers and pain during orthodontic treatment. Comm Dent Oral Epidemiol 1987 ; $15(2): 104-7$.

8. Asher C, Shaw WC. Benzydamine hydrochloride in the treatment of ulceration associated with recently placed fixed orthodontic appliances. Eur J Clin Pharmacol 1986; 31 (2):127-31. 